\title{
Early Increases in Brain myo-Inositol Measured by Proton Magnetic Resonance Spectroscopy in Term Infants with Neonatal Encephalopathy
}

\author{
NICOLA J. ROBERTSON, RACHAEL H. LEWIS, FRANCES M. COWAN, JOANNA M. ALLSOP, \\ SERENA J. COUNSELL, A. DAVID EDWARDS, AND I. JANE COX \\ Division of Paediatrics, Obstetrics, and Gynaecology, Department of Paediatrics [N.J.R., R.H.L., F.M.C., \\ J.M.A., A.D.E.], MRC Clinical Sciences Centre [S.J.C., A.D.E.], and Imaging Sciences Department, \\ Clinical Sciences Centre [I.J.C.], Faculty of Medicine, Imperial College of Science, Technology and \\ Medicine, Hammersmith Hospital Campus, London W12 OHS, United Kingdom
}

\begin{abstract}
Our aim was to assess brain myo-inositol/creatine plus phosphocreatine $(\mathrm{Cr})$ in the first week in term infants with neonatal encephalopathy using localized short echo time proton magnetic resonance spectroscopy and to relate this to measures of brain injury, specifically lactate/Cr in the first week, basal ganglia changes on magnetic resonance imaging (MRI), and neurodevelopmental outcome at $1 \mathrm{y}$. Fourteen term infants with neonatal encephalopathy of gestational age (mean \pm SD) $39.6 \pm 1.6 \mathrm{wk}$, birth weight $3270 \pm 490 \mathrm{~g}$, underwent MRI and magnetic resonance spectroscopy at $3.5 \pm 2.1 \mathrm{~d}$. Five infants were entered in a pilot study of treatment with moderate whole-body hypothermia for neonatal encephalopathy; two were being cooled at the time of the scan. $\mathrm{T}_{1}$ - and $\mathrm{T}_{2}$-weighted transverse magnetic resonance images were graded as normal or abnormal according to the presence or absence of the normal signal intensity of the posterior limb of the internal capsule and signal intensity changes in the basal ganglia. Localized proton magnetic resonance spectroscopy data were obtained from an $8-\mathrm{cm}^{3}$ voxel in the basal ganglia using echo times of 40 and $270 \mathrm{~ms}$, and the peak area ratios of $m y o$-inositol/Cr and lactate/Cr were measured. Outcome was scored using Griffith's development scales and neurodevelopmental examination at $1 \mathrm{y}$. MRI and outcome were normal in six infants and abnormal in eight. $m y o-\mathrm{Inositol} / \mathrm{Cr}$ and lactate $/ \mathrm{Cr}$ were higher in infants with abnormal MRI and outcome $(p<$ $0.01, p<0.01$, respectively). myo-Inositol/Cr and lactate/Cr
\end{abstract}

\section{ABSTRACT}

were correlated $(p<0.01)$ and were both correlated to the Griffith's developmental scales $(p<0.01, p<0.01$, respectively). In conclusion, these preliminary data suggest that early increases in brain basal ganglia $m y o-$ inositol/Cr in infants with neonatal encephalopathy are associated with increased lactate $/ \mathrm{Cr}$, MRI changes of severe injury, and a poor neurodevelopmental outcome at 1 y. (Pediatr Res 50: 692-700, 2001)

$\quad$ Abbreviations
MRS, magnetic resonance spectroscopy
HI, hypoxia-ischemia
MRI, magnetic resonance imaging
TE, echo time
PLIC, posterior limb of the internal capsule
Cr, creatine plus phosphocreatine
NAA, $N$-acetyl-aspartate
NE, neonatal encephalopathy
SMIT, Na ${ }^{+}$/myo-inositol cotransporter
MR, magnetic resonance
OS, optimality score
SI, signal intensity
PRESS, point-resolved spectroscopy
Cho, choline-containing compounds
DQ, development quotient

Cellular adaptation to osmotic stress is a vital process that protects cells from the effects of dehydration or edema. To maintain homeostasis cells produce osmolytes, molecules designed to create osmolality without compromising other cell functions (1).

Received August 23, 2000; accepted May 16, 2001.

Correspondence and reprint requests: Nicola Robertson, MD, Department of Pediatrics, Faculty of Medicine, Imperial College, Hammersmith Hospital, Du Cane Road, London W12 0HS, United Kingdom; e-mail: n.robertson@ic.ac.uk

This work was supported by Marconi Medical Systems, Cleveland, OH, U.S.A., the Garfield Weston Foundation, and the Medical Research Council.
Osmolytes appear to be especially important in the brain as alterations in ion composition would affect excitability. myoInositol is one of the major osmolytes present in the CNS; others include sorbitol, taurine, betaine, and glycerophosphocholine.

myo-Inositol transport inside cells comprises uptake, which is selective and actively driven by SMIT (2), and efflux, which is nonselective and passively mediated by the chloride or volume-sensitive organic osmolyte-anion channel (3). Clinical studies have shown that brain cells respond to extracellular hypertonicity by increasing intracellular concentrations of 
myo-inositol (4). Exposure of neuronal cells (5), astrocytes (6), and glial cells (7) to enhanced extracellular osmolality in vitro was found to stimulate the expression of SMIT mRNA and hence increased intracellular myo-inositol.

Several studies in different species have shown that brain osmolality is increased by brain ischemia $(8,9)$. In adult rats with unilateral cerebral ischemia, SMIT expression was induced 6-72 $\mathrm{h}$ after the insult on both the affected and contralateral sides $(10,11)$. Work using the voltage-gated sodiumchannel opener, veratridine, suggested that the increase in sodium influx caused by sodium-channel opening during the first stage of ischemia or injury may be the trigger for upregulation of SMIT (12).

Brain energy metabolism after perinatal $\mathrm{HI}$ has been extensively investigated using phosphorus $\left({ }^{31} \mathrm{P}\right)$ MRS and long TE proton $\left({ }^{1} \mathrm{H}\right) \mathrm{MRS}$ in both experimental neonatal animal models $(13,14)$ and term infants with NE $(15,16)$. These studies have supported a biphasic model of injury. In animals during HI there was an increase in brain lactate, which recovered on resuscitation. In both animal models and term infants with NE, during a secondary phase $8-12 \mathrm{~h}$ later there was further disruption of brain energy metabolism with a secondary increase in brain lactate. In infants with NE, the magnitude of the secondary derangement in brain energy metabolism was associated with the infant's neurodevelopmental outcome at $1 \mathrm{y}$ (15-19).

Early MRI findings associated with severe perinatal HI brain injury in term infants with $\mathrm{NE}$ include damage to the deeper structures of the brain such as the basal ganglia and thalami and absence of the normal high SI in the posterior half of the PLIC on $\mathrm{T}_{1}$-weighted images (20).

Because myo-inositol is best measured using the technically more challenging short TE ${ }^{1} \mathrm{H} \mathrm{MRS}$, in vivo data documenting acute changes in brain myo-inositol after perinatal HI have not been reported to date. The aim of this study was to investigate the early changes in myo-inositol/Cr using localized short TE
${ }^{1} \mathrm{H}$ MRS in infants with NE and to relate these findings to the following measures of brain injury: 1) basal ganglia lactate/Cr obtained using localized ${ }^{1} \mathrm{H}$ MRS at long TEs, 2) acute changes on MRI, and 3) neurodevelopmental outcome at $1 \mathrm{y}$. We hypothesized that brain $m y o$-inositol/Cr would be increased in the acute to subacute stages after perinatal $\mathrm{HI}$ as a response 1) to extracellular hypertonicity and induction of SMIT and 2) to decreased cellular ATP levels leading to decreased efflux of myo-inositol (21).

\section{METHODS}

Permission for this prospective MR study was granted by the Hammersmith Hospital Research Ethics Committee (number 93/4047), and parental consent was obtained for each study.

Subjects. Term infants were selected for inclusion into the MR study according to at least one of the following criteria: history of fetal distress [late decelerations on cardiotocography, meconium-stained liquor, acidemia $(\mathrm{pH}<7.1$ or base deficit $>12 \mathrm{mM}$ ) in umbilical cord blood or arterial blood within $30 \mathrm{~min}$ of birth] and early abnormal postnatal neurologic signs consistent with NE.

The study population consisted of 14 infants born at gestational age (mean $\pm \mathrm{SD}$ ) of $39.6 \pm 1.6 \mathrm{wk}$ and having a birth weight of $3270 \pm 490 \mathrm{~g}$. Infants were examined using MRI and localized ${ }^{1} \mathrm{H}$ MRS at $3.5 \pm 2.1 \mathrm{~d}$. Five infants had been entered into the pilot study of treatment with whole-body hypothermia for NE [Hammersmith Hospital Research Ethics Committee number $97 / 5133$; (22)], and two were being cooled at the time of the scan. Clinical data are summarized in Table 1.

In the five infants (patients 7, 9, 12,13, and 14) who were selected to receive the hypothermia treatment, hypothermia was initiated within $6 \mathrm{~h}$ of birth and maintained using a commercial air-cooling system (Polar Air, Augustine Medical, Eden Prairie, MN, U.S.A.), which induced hypothermia by blowing cool air through a translucent, perforated paper blan-

Table 1. Clinical details of birth-asphyxiated infants

\begin{tabular}{|c|c|c|c|c|c|c|c|c|c|c|c|c|c|}
\hline \multicolumn{11}{|c|}{ Clinical details } & \multicolumn{3}{|c|}{ Outcome } \\
\hline Patient & $\begin{array}{l}\text { GA } \\
\text { (wk) }\end{array}$ & $\begin{array}{l}\text { BW } \\
(\mathrm{g})\end{array}$ & $\begin{array}{l}\text { Mode of } \\
\text { delivery }\end{array}$ & $\begin{array}{c}\text { Evidence of fetal } \\
\text { distress }\end{array}$ & Apgars* & $\begin{array}{c}\text { Mode of } \\
\text { resuscitation }\end{array}$ & $\begin{array}{c}\text { Cord blood } \\
\mathrm{pH}\end{array}$ & $\begin{array}{c}\text { Base } \\
\text { excess }\end{array}$ & $\mathrm{NE} \dagger$ & Cooled & $\begin{array}{l}\text { Griffith's } \\
\text { DQ }\end{array}$ & $\begin{array}{c}\text { Optimality } \\
\text { score }\end{array}$ & $\begin{array}{l}\text { Outcome } \\
\text { category }\end{array}$ \\
\hline 1 & 40 & 3380 & Forceps & CTG & $5^{1}, 9^{5}$ & Et & NR & NR & 2 & no & 110 & 75 & normal \\
\hline 2 & 41 & 4100 & NVD & shoulder dystocia & $5^{10}$ & $\mathrm{Et}$ & 6.8 & -20.6 & 1 & no & 105 & 72 & normal \\
\hline 3 & 42 & 3765 & Em CS & $\mathrm{CTG} / \mathrm{Mec}$ & $6^{1}, 9^{5}$ & $\begin{array}{l}\text { Bag and } \\
\text { mask }\end{array}$ & 7.2 & -4.7 & 1 & no & 110 & 75 & normal \\
\hline 4 & 41 & 2680 & Em CS & CTG & $1^{1}, 5^{5}$ & Et & 6.8 & -22 & 1 & no & 106 & 75 & normal \\
\hline 5 & 38 & 2580 & Em CS & $\mathrm{CTG} / \mathrm{Mec}$ & $1^{1}, 4^{5}$ & Et & 6.73 & -20.3 & 2 & no & 106 & 73 & normal \\
\hline 6 & 40 & 3000 & Em CS & CTG & $0^{1}, 4^{5}$ & Et & 6.82 & -14 & 2 & no & 105 & 66 & abnormal \\
\hline 7 & 38 & 3680 & NVD & none & $0^{1}, 0^{5}, 0^{10}$ & Et,Ad,CM & 7.27 & NR & 2 & yes & 99 & 66 & abnormal \\
\hline 8 & 38 & 2470 & NVD & none & $1^{1}, 5^{5}$ & Et & 7.2 & -8.9 & 2 & no & 96 & 75 & normal \\
\hline 9 & 37 & 3460 & El CS & CTG & $3^{1}, 3^{5}$ & Et,CM & 6.73 & -25.5 & 2 & yes & 93 & 68 & abnormal \\
\hline 10 & 38 & 2990 & Em CS & CTG & $0^{1}$ & Et,Ad,CM & 7.35 & -1.5 & 2 & no & 70 & 55 & abnormal \\
\hline 11 & 41 & 3030 & NVD & $\mathrm{CTG} / \mathrm{Mec}$ & $1^{1}, 2^{5}$ & Et & 7.03 & -17 & 2 & no & 54 & 46 & abnormal \\
\hline 12 & 41 & 3830 & Ventouse & CTG & $1^{1}, 1^{5}$ & Et,Ad,CM & 7.22 & NR & 2 & yes & 50 & 40 & abnormal \\
\hline 13 & 39 & 3515 & Breech & $\mathrm{CTG} / \mathrm{Mec}$ & $0^{1}, 0^{5}$ & Et,Ad,CM & 6.5 & -31 & 3 & yes & $<20$ & 0 & dead \\
\hline 14 & 41 & 3350 & Em CS & $\mathrm{CTG} / \mathrm{Mec}$ & $0^{1}, 2^{5}$ & Et,Ad,CM & 7.08 & -11 & 3 & yes & $<20$ & 0 & dead \\
\hline
\end{tabular}

* Superscript numerals indicate minutes after delivery at which Apgar score was determined.

Abbreviations used: GA, gestational age; BW, birth weight; NVD, normal vaginal delivery; Em CS, emergency cesarean section; El CS, elective cesarean section; CTG, cardiotocography; Mec, meconium; Et, endotracheal intubation and ventilation; Ad, adrenaline; CM, cardiac massage; NR, not recorded.

$\uparrow$ Number refers to clinical grade of encephalopathy. 
ket placed over the infant. The air temperature was adjusted to maintain the rectal temperature between 33 and $34^{\circ} \mathrm{C}$ for $48 \mathrm{~h}$. Using an extension to the air-cooling system this treatment could be continued while the infant was being studied in the magnet (patients 13 and 14). After $48 \mathrm{~h}$ of hypothermia the infant was rewarmed at $0.5^{\circ} \mathrm{C} / \mathrm{h}$. Patients 7,9 , and 12 were studied after $48 \mathrm{~h}$ of hypothermia when they were normothermic.

The MRI and MRS examinations were performed sequentially in natural sleep or after sedation with oral chloral hydrate $(50-100 \mathrm{mg} / \mathrm{kg})$ in infants who were self-ventilating and i.v. morphine infusion in those requiring mechanical ventilation. For immobilization and noise damping, the infant's head was partly surrounded by a bag filled with polystyrene balls from which the air was evacuated. Neonatal intensive care, including mechanical ventilation, i.v. fluids, and inotropic drug administration, was continued as appropriate during the scans, and all infants were accompanied by one pediatrician at all times. Heart rate, oxygen saturation, and axillary and rectal temperatures in those infants being cooled were monitored throughout the procedure. Mechanical ventilation was provided if necessary by an MR-compatible neonatal ventilator (babyPAC Neonatal Ventilator, pneuPAC Limited, Luton Beds, England).

Magnetic resonance imaging. Cerebral MR data were obtained using a Marconi Medical prototype 1.5-T MR system (Marconi Medical Systems, Cleveland, OH, U.S.A.) and a double-tuned pediatric birdcage coil. The study protocol consisted of multislice $T_{1}$-weighted conventional spin echo (CSE $500 / 15$ ) and dual proton-density, $\mathrm{T}_{2}$-weighted fast spin echo (FSE TR 4200 TE 15/210) transverse images and sagittal $\mathrm{T}_{1}$-weighted conventional spin echo images. Infants were divided into two groups by analysis of the MR images by a researcher blinded to the MRS results. The appearance of the SI of the PLIC was assessed on both the $\mathrm{T}_{1}$ - and $\mathrm{T}_{2}$-weighted images and graded as normal or abnormal. In some cases the SI from the PLIC was equivocal because of a delay in the evolution of the loss of signal. In these situations the basal ganglia were assessed for the presence of other areas of abnormal SI, and if present the MR image was classified as abnormal.

Magnetic resonance spectroscopy. A voxel $(2 \mathrm{~cm} \times 2 \mathrm{~cm} \times$ $2 \mathrm{~cm}$ ) within the basal ganglia was defined, and ${ }^{1} \mathrm{H}$ MR spectra localized to this voxel were obtained using the PRESS localization sequence (23), with computer-optimized slice-selective radio-frequency pulses, using a repetition time of $2 \mathrm{~s}, 128$ data collections, and TE values of 40 and $270 \mathrm{~ms}$. Water suppression was obtained with three initial chemical shift-selective saturation pulses. The voxel was placed in the basal ganglia on the left side in all cases and not specifically from an area including any lesion.

The ${ }^{1} \mathrm{H}$ MR data were filtered using a Gaussian filter (line broadening, $1.5 \mathrm{~Hz}$ ), Fourier transformed, and manually phased. The singlet peaks were routinely assigned at both long and short TEs to Cho (3.22 ppm), Cr (3.02 ppm), and NAA $(2.02 \mathrm{ppm})$. The methyl group of lactate was a doublet centered at $1.34 \mathrm{ppm}$ at TE $270 \mathrm{~ms}$. At TE $40 \mathrm{~ms}$ the lactate peak overlapped with lipid and macromolecule resonances, and no attempt was made to separate the contributions. The MR spectrum of myo-inositol (3.56 ppm) was particularly complex because the six protons have similar but slightly different chemical shifts. The coupling pattern at $1.5 \mathrm{~T}$ was not first order; however, many authors have described how myoinositol can be characterized at TE $40 \mathrm{~ms}$ by a singletlike peak at $3.56 \mathrm{ppm}$ within the spectral resolution achieved in a clinical scanner $(24,25)$. The resonance at $3.56 \mathrm{ppm}$ may also contain smaller contributions from inositol monophosphate, inositol polyphosphates, and glycine. In principle, definitive assignment to myo-inositol could be confirmed by quantifying the other myo-inositol resonance at $4.1 \mathrm{ppm}$. This peak, however, could not be reliably fitted because of its proximity to the residual water signal, and therefore it was not possible to precisely determine contributions other than myo-inositol. A complex multiplet could also be assigned to glutamine/ glutamate (2.14-2.47 ppm).

Peak area ratios were calculated by fitting the peaks to a combined Lorentzian/Gaussian line shape. The starting point of the line-fitting algorithm was, first, to specify the expected resonances and then to limit the line width so that overlapping peaks were not obscured by a spurious fit to a broad resonance. For the spectra acquired with TE $40 \mathrm{~ms}$, the maximum peak width of the fitted line shapes was limited to $0.1 \mathrm{ppm}$. The peak area ratio of $m y o$-inositol/Cr was measured from the spectrum acquired using TE $40 \mathrm{~ms}$, and lactate/ $\mathrm{Cr}$ and $\mathrm{NAA} / \mathrm{Cr}$ were measured from the spectrum acquired with TE $270 \mathrm{~ms}$.

Neurodevelopmental outcome. Neurodevelopmental outcome was assessed at $1 \mathrm{y}$ of age using Griffith's DQ (26) and a detailed neurologic examination quantified with an OS (27). This score included items for tone, posture, passive and elicited motility and tone, interaction, reflexes, and vision and hearing responses. Infants were classified as normal if they had no abnormal neurologic signs (that is, a normal OS) and achieved a Griffith's DQ of $>85$. All other infants were regarded as having an abnormal neurodevelopmental outcome. Infants who died in this study did so because of neurologic problems and were scored with a DQ of $<20$.

Statistical considerations. Data distributions were inspected and were transformed to normality when appropriate. ANOVA was used to compare the mean myo-inositol/Cr, lactate $/ \mathrm{Cr}$, $\mathrm{NAA} / \mathrm{Cr}$, and $\mathrm{Cho} / \mathrm{Cr}$ in the group with normal MRI and outcome with the spectroscopy findings in the group with abnormal MRI and outcome. Regression analysis was used to compare spectroscopy findings with the Griffith's DQ. Results are presented as mean $\pm \mathrm{SD}$.

\section{RESULTS}

The MRI and MRS data in all infants were acquired at $3.5 \pm$ $2.1 \mathrm{~d}$ after birth. MRI grading and MRS results for each infant are illustrated in Table 2. Representative MR images and ${ }^{1} \mathrm{H}$ MR spectra are illustrated in Figures 1 and 2.

The serum sodium concentrations and osmolality are given in Table 2. In patient 11 the increase in osmolality was transient.

Six infants had normal MRI and eight infants had abnormal MRI of the basal ganglia and PLIC. There was no evidence of long-standing injury on any of the MR scans. The gestational 


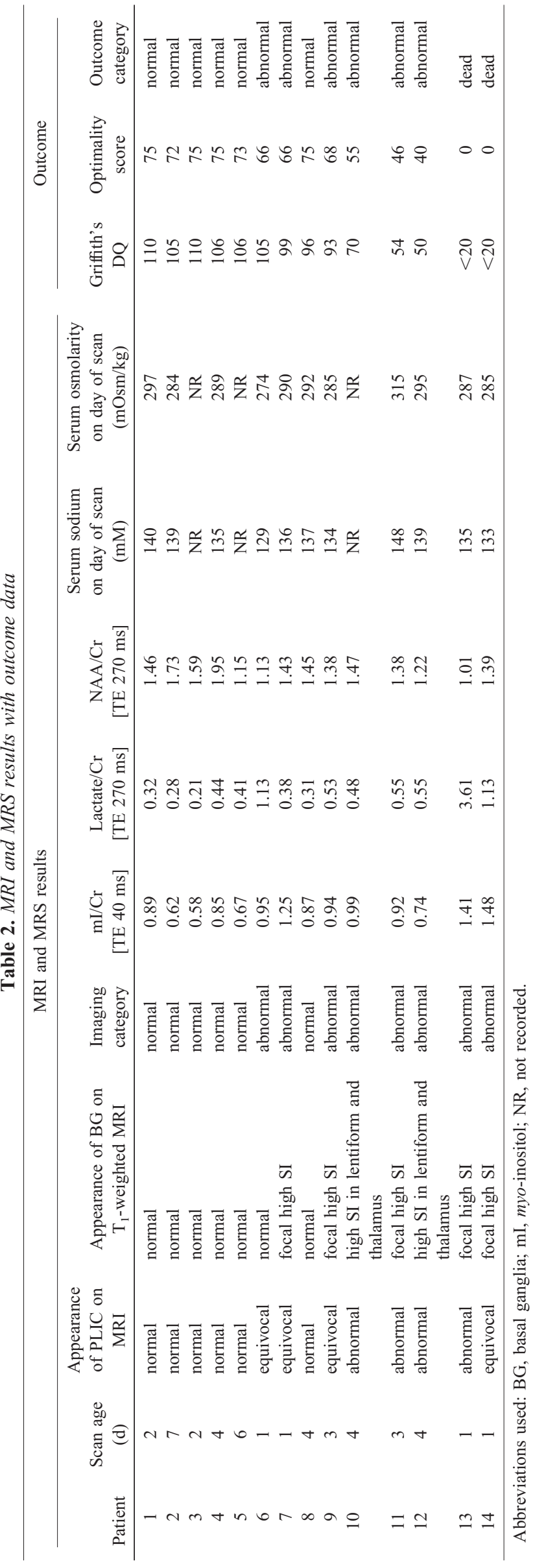

age at birth of those infants with normal MRI was $40.0 \pm 1.7$ wk and in the group with abnormal MRI was $39.4 \pm 1.6 \mathrm{wk}(p$ $>0.05$ ). The birth weight of those infants with normal MRI was $3160 \pm 680 \mathrm{~g}$ and in the group with an abnormal MRI was $3360 \pm 320 \mathrm{~g}(p>0.05)$. The age at time of scan in the group with infants with normal MRI was $4.5 \pm 2.2 \mathrm{~d}$ and in the group with abnormal MRI was $2.7 \pm 1.8 \mathrm{~d}(p>0.05)$.

All infants with normal MRI $(n=6)$ had a normal outcome at $1 \mathrm{y}$; none of these infants had been cooled. All those infants with abnormal MRI $(n=8)$ had an abnormal outcome at $1 \mathrm{y}$; five of these infants had been cooled.

For all infants $m y o$-inositol/ $\mathrm{Cr}$ and lactate/Cr were significantly correlated $(p<0.01 ;$ Fig. 3$)$. This relationship remained significant when the two infants who were cooled at the time of the study were excluded $(p<0.05)$. For all infants myoinositol/Cr was not related to $\mathrm{NAA} / \mathrm{Cr}$ or $\mathrm{Cho} / \mathrm{Cr}$.

The myo-inositol/Cr in the infants with normal MRI and outcome was $0.75 \pm 0.14$ and in the group with abnormal MRI and outcome, $1.09 \pm 0.26(p=0.05$; Fig. $4 A)$. There was a relation between the Griffith's developmental scale at $1 \mathrm{y}$ of age and the $m y o$-inositol/ $\mathrm{Cr}$ ratio in the basal ganglia in the first week $(p<0.01$; Fig. $4 B)$.

The lactate/Cr in the infants with normal MRI and outcome was $0.34 \pm 0.08$ and in the group with abnormal MRI and outcome, $1.05 \pm 1.08$ ( $p<0.01$; Fig. 5). There was a relation between the Griffith's developmental scale at $1 \mathrm{y}$ of age and the lactate/Cr ratio in the basal ganglia in the first week $(p<0.01)$.

The NAA/Cr in the infants with normal MRI and outcome was $1.56 \pm 0.27$ and in the group with abnormal MRI and outcome, $1.30 \pm 0.16$ ( $p=0.06$; Fig. 6). There was no association between the Griffith's developmental scale at $1 \mathrm{y}$ of age and the NAA/Cr ratio in the basal ganglia in the first week.

The $\mathrm{Cho} / \mathrm{Cr}$ in the patients with normal MRI and outcome was $2.18 \pm 0.32$ and in the group with abnormal MRI and outcome, $1.97 \pm 0.33(p=0.3)$. There was no association between the Griffith's developmental scale at $1 \mathrm{y}$ of age and the $\mathrm{Cho} / \mathrm{Cr}$ ratio in the basal ganglia in the first week.

\section{DISCUSSION}

This study found that myo-inositol/Cr was increased in the basal ganglia in the first week after birth in infants with NE who have sustained a severe HI brain injury as evidenced by MRI, basal ganglia lactate/Cr ratios, and neurodevelopmental outcome at 1 y. $m y o-I n o s i t o l / C r$ was correlated to lactate/Cr.

Term infants up to $1 \mathrm{wk}$ (mean age, $3.5 \pm 2.1 \mathrm{~d}$ ) of age only were studied for the following reasons. First, it was important to examine the acute brain changes because in vitro work has demonstrated up-regulation of SMIT up to $48 \mathrm{~h}$ after an insult (9). Second, as brain myo-inositol concentrations are known to decrease with increasing postnatal age (28), confounding effects because of age were limited. Third, metabolite changes occurring with secondary energy failure were likely to have developed by $1-3 \mathrm{~d}$ and this was therefore an appropriate time to acquire data. Unfortunately, at this early stage after perinatal HI injury, MRI changes are still evolving unless they are of antenatal onset. Loss of the normal SI of the PLIC may take 1-2 d to be evident on conventional $T_{1}$ - and $T_{2}$-weighted 
a)

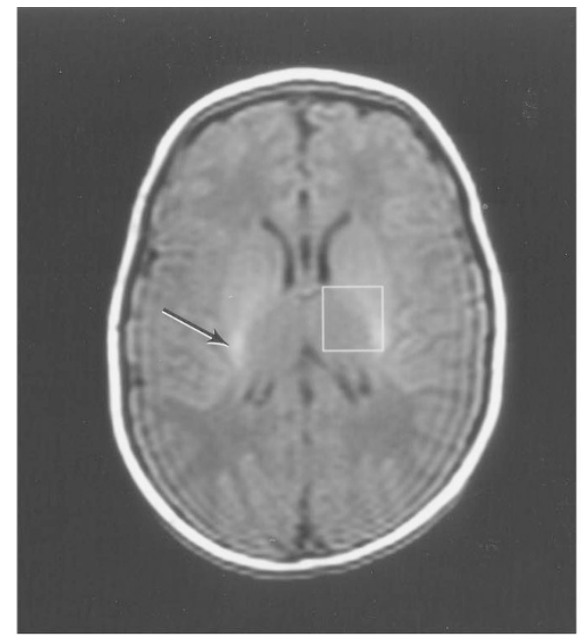

b)

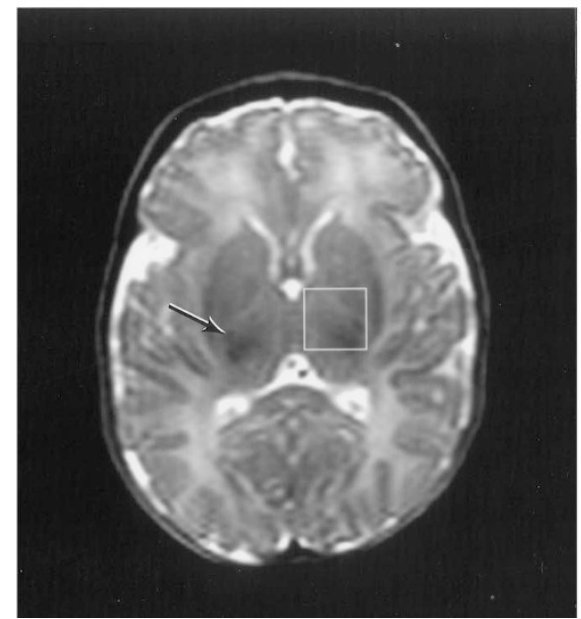

c)

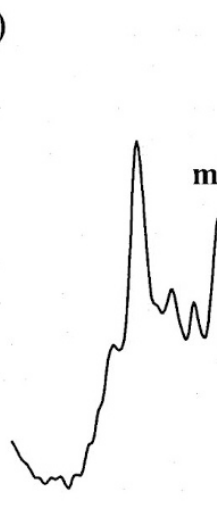

Cho
TE $40 \mathrm{~ms}$

m I/Cr 0.85 d)

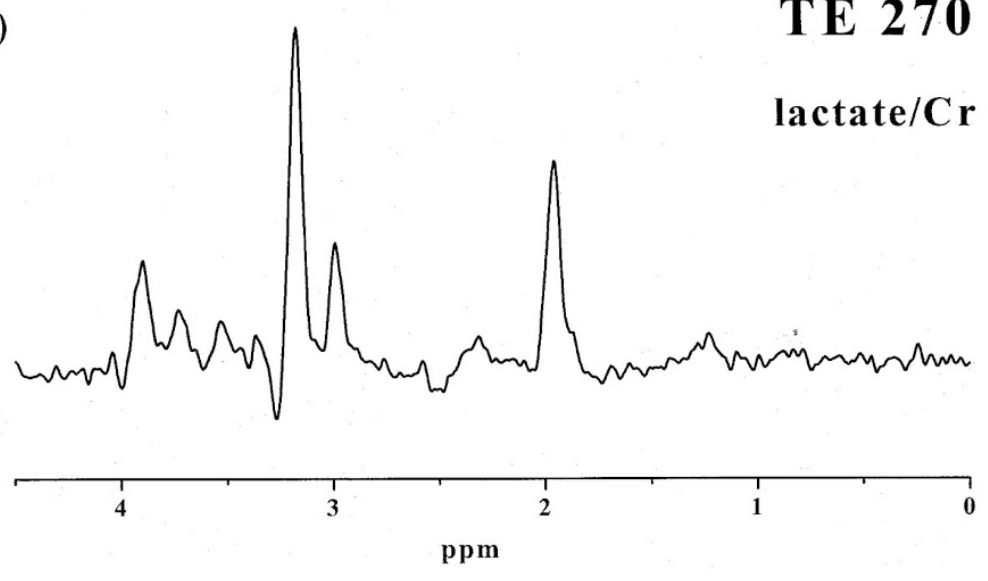

Figure 1. Infant born at $41 \mathrm{wk}$ gestational age by emergency cesarean section with Apgar scores of 1 at 1 min and 5 at 5 min (patient 4 ). The infant was examined by MRI and MRS on $\mathrm{d} 4$. This infant had normal MRI and a normal neurodevelopmental outcome at $1 \mathrm{y}$ of age. $A, \mathrm{~T}_{1}$-weighted (conventional spin echo 500/15) transverse MR image illustrating bilateral high SI from myelin in the posterior half of the PLIC (arrow). The position of the 8-cm ${ }^{3}$ voxel from which the ${ }^{1} \mathrm{H}$ MRS data were obtained is shown. $B, \mathrm{~T}_{2}$-weighted (fast spin echo 4200/15/210) transverse MR image demonstrating bilateral regions of low SI representing myelin in the PLIC (arrow). $C,{ }^{1} \mathrm{H}$ MR spectrum acquired from the voxel shown in $A$ and $B$ using PRESS localization sequence, TE 40 ms. myo-Inositol $(\mathrm{mI}) / \mathrm{Cr}$ was $0.85 . D$, localized ${ }^{1} \mathrm{H}$ MR spectrum acquired using TE $270 \mathrm{~ms}$. Lactate $/ \mathrm{Cr}$ was 0.44 .

images after $\mathrm{HI}$; for example, before d 3 the presence or absence of the PLIC has a $91 \%$ positive predictive value for outcome whereas after $\mathrm{d} 3$ the predictive value is $100 \%(20)$. For this reason we also took into account global SI changes in the basal ganglia to categorize the MR images into normal and abnormal groups.

The impact of mild hypothermia on the rate of evolution of MR changes and the severity of the brain injury are important considerations. MRS changes have been studied in experimental animal models; mild hypothermia started after severe transient $\mathrm{HI}$ in the newborn piglet reduced the delayed elevation in lactate peak area ratios (29) and the delayed cerebral energy failure measured by phosphocreatine to inorganic phosphate ratio (30). Although there are no MRS data in the newborn infant during or after cooling, the secondary rise in brain lactate/Cr is likely to have been ameliorated by cooling. Five of the eight infants with abnormal outcome were cooled; none of the six infants with a normal outcome were cooled. However, there was still a significant difference in lactate/Cr between outcome groups. The effect of cooling on brain myo-inositol concentrations or the activity of SMIT is unknown. Clinically relevant effects of hypothermia include mild hypokalemia (31), suppression of antidiuretic hormone release causing a diuresis, and a reduction in renal blood flow and GFR (32). In our pilot study of mild hypothermia, although cooled infants had a mild metabolic acidosis, a slightly raised blood lactate, and a relative hypokalemia, there was no significant change in plasma osmolality (22). Although it is not impossible that hypothermia may lead to an increase in myo-inositol concentrations, this is unlikely and hypothermia could not account for the increased myo-inositol concentrations seen in the infants who were cooled. Thus although the effect of cooling warrants further study it is unlikely that our results can be explained by this alone.

Metabolite ratios were used in this study as it was difficult to acquire a sufficient amount of data during the examination in these unstable patients to achieve reliable absolute quantification. Furthermore, the use of water as an internal reference may be problematic in this group of patients because both the water concentration and relaxation parameters may be changing in 


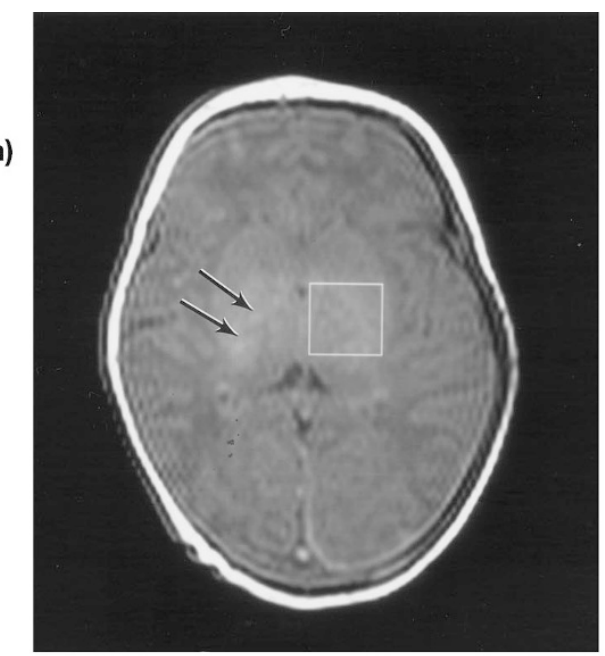

c)
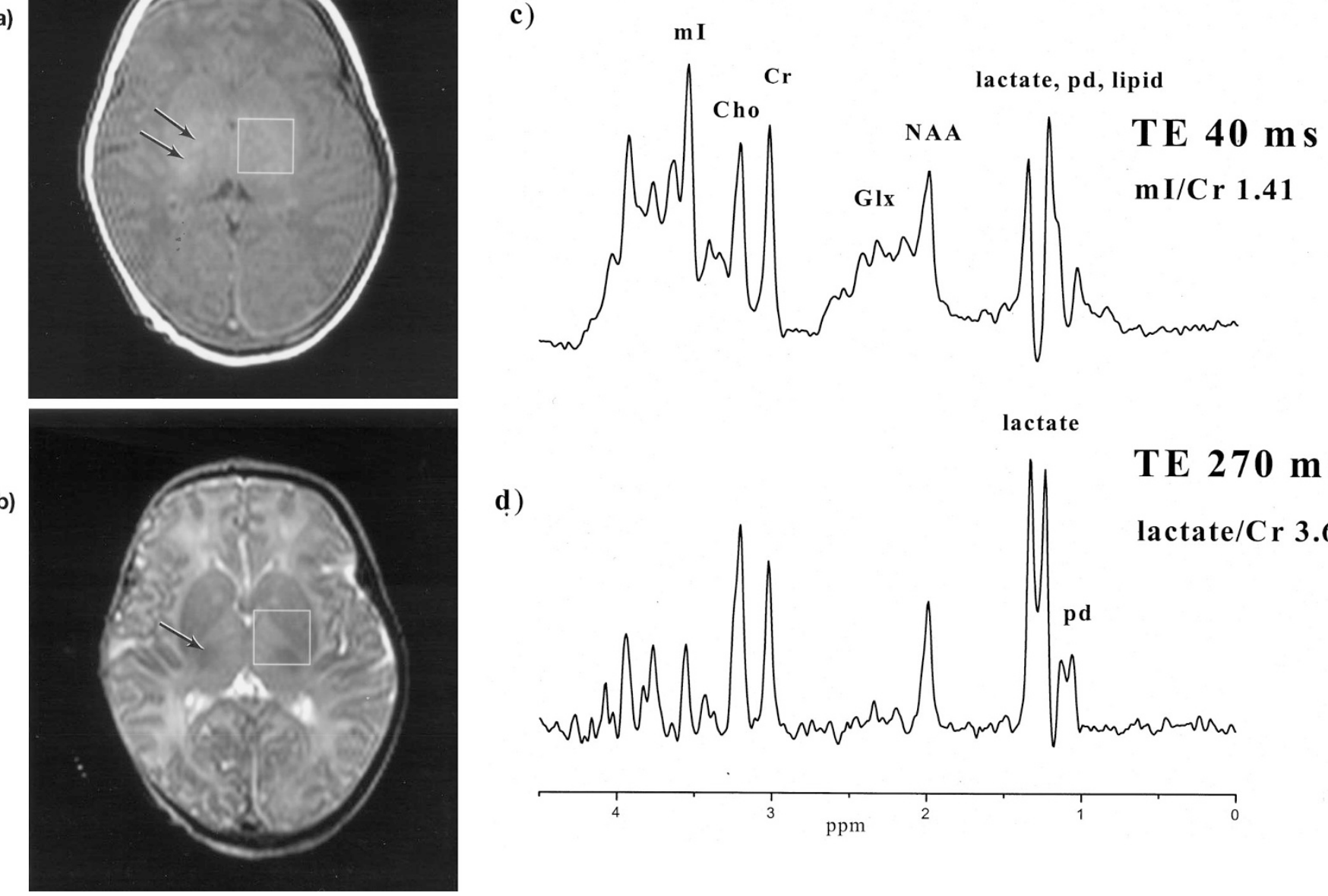

Figure 2. Infant born at $39 \mathrm{wk}$ gestational age by assisted breech delivery with Apgar scores of 0 at $1 \mathrm{~min}$ and 0 at 5 min (patient 13). This infant was enrolled at $<6 \mathrm{~h}$ of age into the pilot study of treatment with whole-body hypothermia for NE. MRI and MRS studies were undertaken on $\mathrm{d} 1$ while the patient was being cooled. This infant had abnormal MRI and died on $\mathrm{d} 2$ of age. $A$, $\mathrm{T}_{1}$-weighted (conventional spin echo 500/15) transverse MR image illustrating loss of the $\mathrm{SI}$ from the PLIC (arrow). There is evidence of brain swelling. There are some small abnormal SIs in the basal ganglia and thalami (arrows). The position of the $8-\mathrm{cm}^{3}$ voxel from which the ${ }^{1} \mathrm{H}$ MRS data were obtained is shown. $B, \mathrm{~T}_{2}$-weighted (fast spin echo 4200/15/210) transverse MR image. There is no obvious low signal attributable to myelin in the PLIC but an exaggeration of the low SI in the lateral thalamus (arrow). $C,{ }^{1} \mathrm{H}$ MR spectrum acquired from the voxel shown in $A$ and $B$ using PRESS localization sequence, TE $40 \mathrm{~ms}$. Relative $\mathrm{mI}$ levels were increased, as illustrated by the $\mathrm{mI} / \mathrm{Cr}$ metabolite ratio of 1.41 . $D$, localized ${ }^{1} \mathrm{H}$ MR spectrum acquired using TE $270 \mathrm{~ms}$, illustrating markedly elevated lactate/Cr of 3.61 .

areas of gross pathology. We used $\mathrm{Cr}$ as the metabolite of reference for lactate, myo-inositol, NAA, and Cho because $\mathrm{Cr}$ concentrations have been reported to be relatively stable after an HI insult (33). The reported regional variation in metabolite concentrations (34) was avoided as data were specifically collected from the basal ganglia (20).

At short TEs, broad resonances have been reported to be present at $0.9,1.3$, and $2.05 \mathrm{ppm}$; these have been attributed to macromolecules and lipids (35). These compounds have been shown to be increased after HI events (36) and will overlap with the lactate resonance at $1.34 \mathrm{ppm}$ at TE $40 \mathrm{~ms}$; however, it was outside the scope of this study to define the contribution from lipids and macromolecules. At TE $270 \mathrm{~ms}$, signals from these broad compounds are absent, allowing accurate assignment of the resonance at $1.34 \mathrm{ppm}$ to lactate.

We assigned the peak at $3.56 \mathrm{ppm}$ to $m y o$-inositol (37). The comparison of the spectra obtained at TE $270 \mathrm{~ms}$ with those obtained at TE $40 \mathrm{~ms}$ are consistent with this assignment; however, we cannot rule out some contribution from glycine. This deserves further study, for example, using even shorter TEs or higher magnetic fields.

myo-Inositol is one of several osmolytes found in mammalian cells. There are three main groups: polyalcohols, such as sorbitol and myo-inositol; methylamines, such as glycerophosphocholine and betaine; and amino acids, such as glycine, glutamine, glutamate, aspartate, and taurine (38). myo-Inositol is involved in several cellular processes in the CNS. It is perhaps best known for intracellular signal transduction (39); as a precursor of phospholipids and phosphoinositides myo-inositol is also involved in cell membrane structure, adhesion, growth, vesicular trafficking, and survival. Most intracellular myo-inositol, however, is thought to function as a modulator of cell volume during persistent osmotic stress (40); the myo-inositol peak visible by MR represents this free myo-inositol, as myo-inositol 


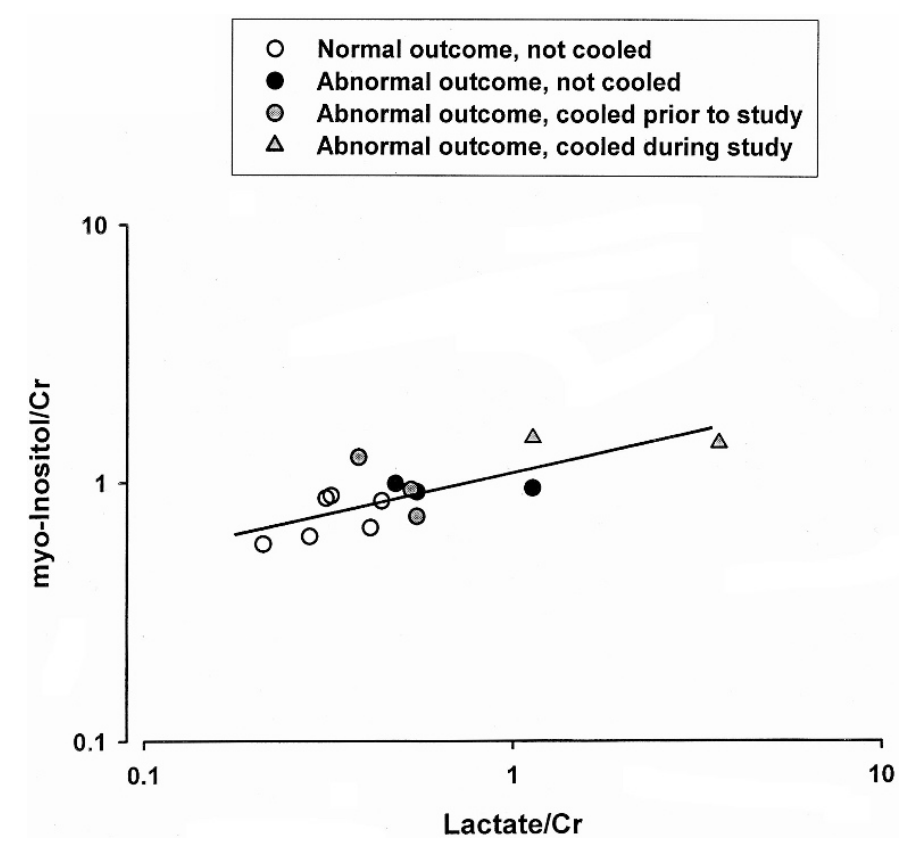

Figure 3. myo-Inositol/Cr versus lactate/ $\mathrm{Cr}$ and the regression line for all infants demonstrating a significant correlation between the two ratios $(p<$ 0.01). $m y o$-Inositol/Cr and lactate/Cr are both plotted on logarithmic scales to enable illustration of the spread of results.

involved in signal transduction is mostly bound and present in very small concentrations (41).

myo-Inositol and its transporter are thought to play an important role in normal fetal brain development; SMIT mRNA is diffusely and abundantly expressed in the fetal rat brain with a down-regulation at birth (42). Reasons for this elevated brain myo-inositol in fetuses are unknown. Clinical MRS studies have demonstrated that myo-inositol concentra- tions decrease after birth in the normal term infant brain and reach adult levels within the first few months of life (28).

The role of myo-inositol in osmoregulation in the CNS has been addressed in clinical studies. Studies using short TE ${ }^{1} \mathrm{H}$ MRS have demonstrated an increase in brain myo-inositol in chronic hypernatremic states (4) and a decrease in myo-inositol in hyponatremic states (43). In all our infants except one the serum sodium and osmolality were within the normal range. In this infant the serum sodium and osmolality were mildly raised (148 $\mathrm{mM}$ and $315 \mathrm{mOsm} / \mathrm{kg}$, respectively); part of the increase in basal ganglia myo-inositol is therefore might be attributable to this but probably minimally so. Excluding this patient from the analysis did not change the significant difference between normal and abnormal groups.

$m y o-I n o s i t o l / C r$ was increased in those infants with abnormal MRI of the basal ganglia and in those infants with an abnormal neurodevelopmental outcome at $1 \mathrm{y}$. There was a correlation between $m y o$-inositol $/ \mathrm{Cr}$ and lactate $/ \mathrm{Cr}$ ratios. A possible explanation for this acute change in myo-inositol $/ \mathrm{Cr}$ may be induction of SMIT $(10,11)$, one of the many gene expressions to be influenced by an acute insult. Activation of SMIT may be in response to the influx of cations occurring during membrane depolarization at the start of the insult. This has been demonstrated with neuronal cells exposed to veratridine (causing cellular uptake of sodium); these cells developed an up-regulation of SMIT mRNA levels (12). Veratridine used with blockade of myo-inositol uptake demonstrated increased cytotoxicity in neuronal cultures, suggesting a possible protective role of myo-inositol. Accumulation of osmolytes is a slow process taking hours or days in contrast to the regulatory cell volume increase that occurs with ions (44). As there are no studies on long-term changes in brain myo-inositol/Cr after $\mathrm{HI}$, a)

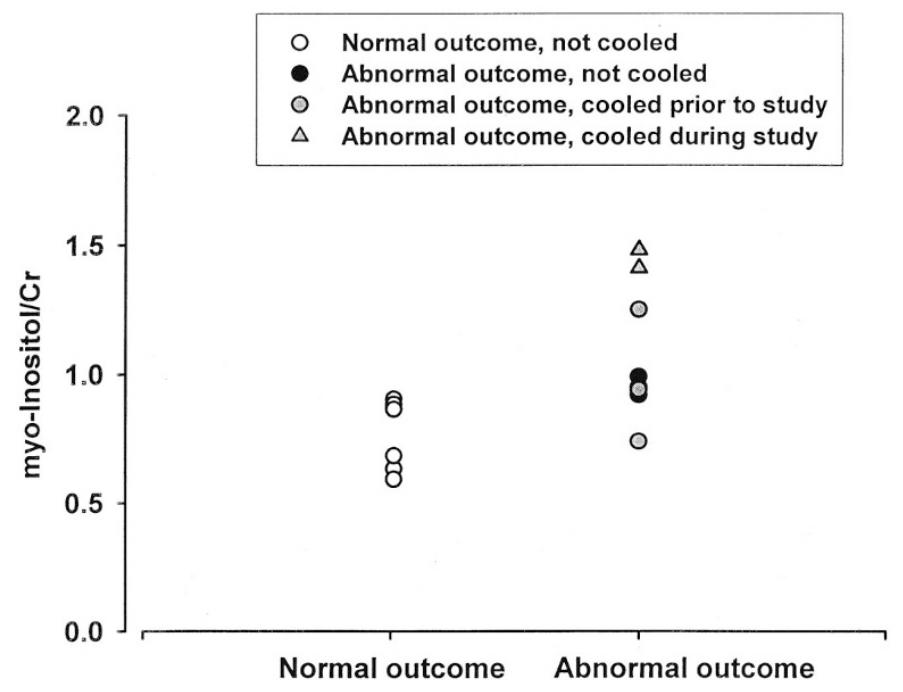

b)

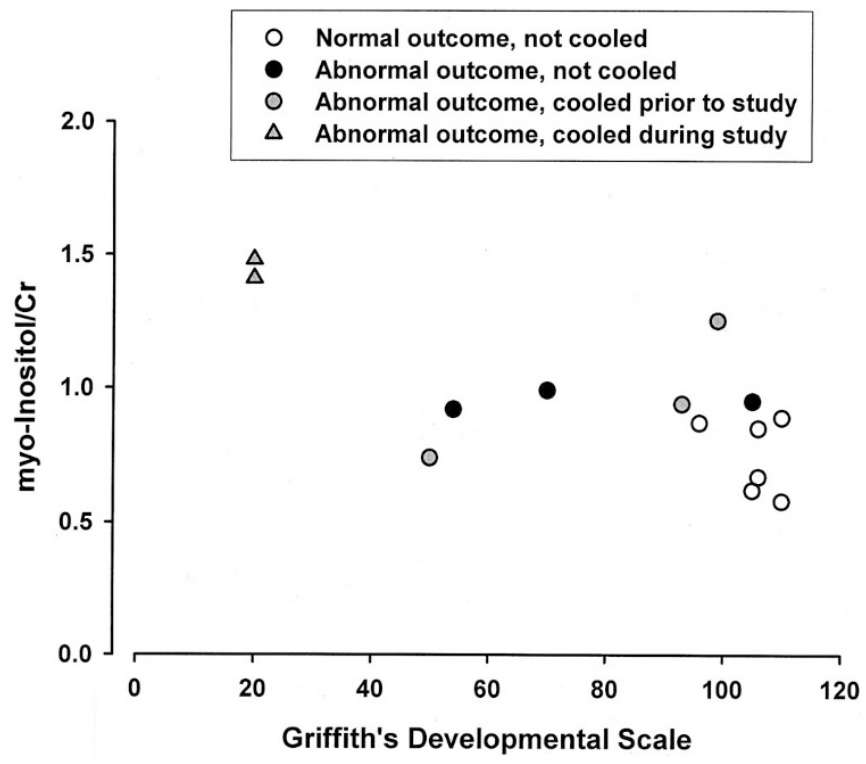

Figure 4. A, myo-inositol/Cr ratios plotted according to normal or abnormal neurodevelopmental outcome. There was a significant difference between groups $(p<0.01) . B$, myo-inositol/Cr in the basal ganglia in the first week plotted against the Griffith's developmental scales at $1 \mathrm{y}$, demonstrating a linear relationship $(p<0.01)$. Those infants with a DQ of 20 died. 


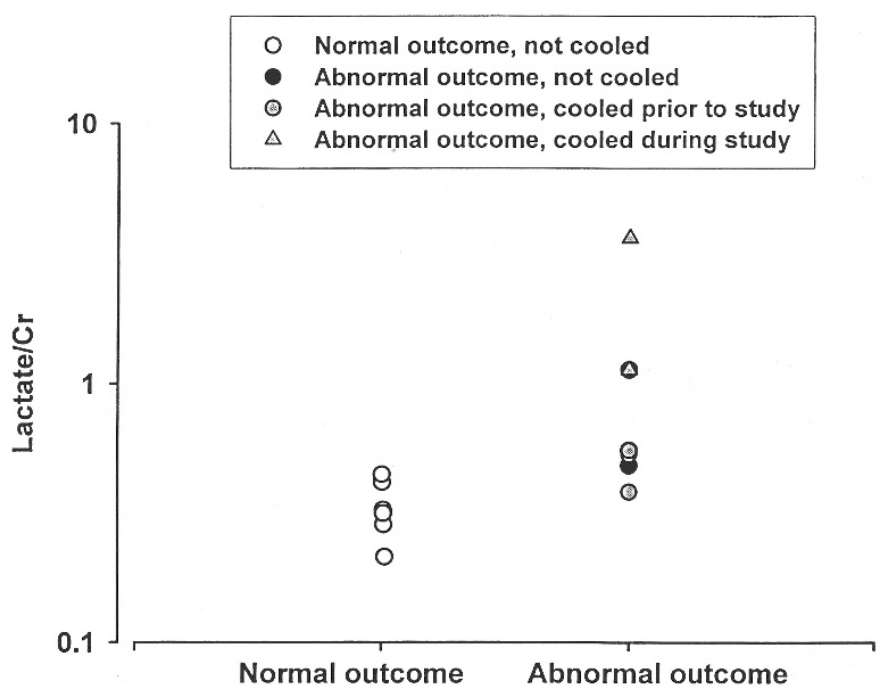

Figure 5. Lactate/Cr ratios plotted according to normal or abnormal neurodevelopmental outcome. Lactate/Cr is plotted on a logarithmic scale to enable illustration of the spread of results. There was a significant difference between groups $(p<0.01)$

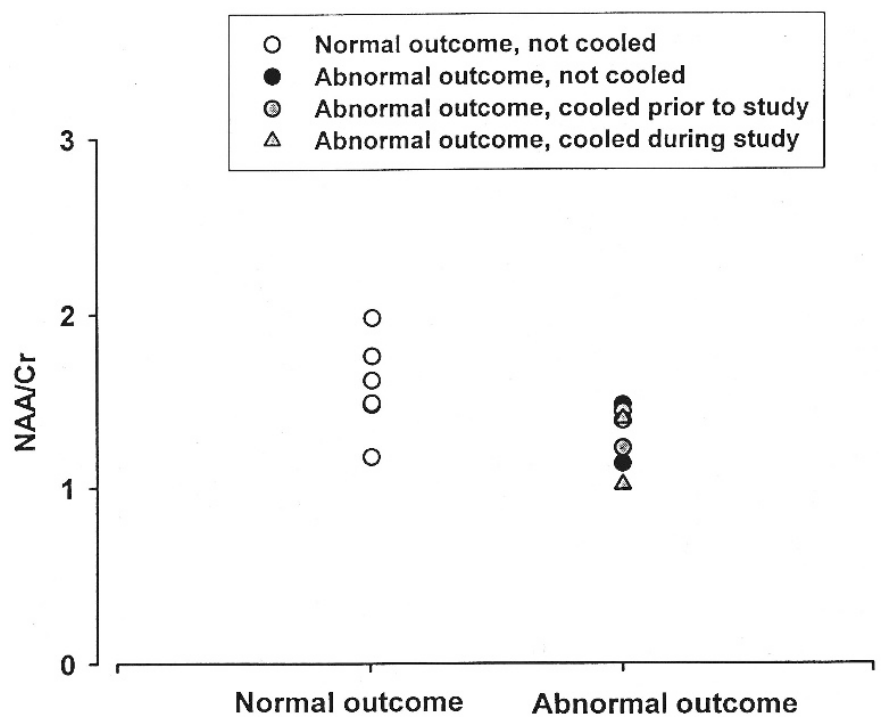

Figure 6. NAA/Cr ratios plotted according to normal or abnormal neurodevelopmental outcome. There was a trend toward a lower $\mathrm{NAA} / \mathrm{Cr}$ in the abnormal group, but this did not reach significance $(p=0.6)$.

it is unclear whether the increase in myo-inositol during the early hours and days after HI persists.

The relative reduction in cellular ATP levels in the injured brain may also lead to increased brain $m y o$-inositol $/ \mathrm{Cr}$ as efflux of myo-inositol from the cell requires the nonhydrolytic association of ATP with the volume-sensitive organic osmolyteanion channel (21). Thus, decreased cellular ATP availability may be associated with decreased myo-inositol release, exacerbating neuronal swelling.

Other disorders associated with increased brain myo-inositol levels include Alzheimer's disease (45), preterm white matter damage at a corrected age of term (46), and Down syndrome (47). In the latter condition, up-regulation of the SMIT gene, which has been mapped to the long arm of chromosome 21
(48), was demonstrated in cultured fibroblasts (49), possibly explaining the increased brain myo-inositol concentrations seen in these patients.

In vitro work has suggested that myo-inositol is a marker for glia (50); clinical studies in adult white matter disease caused by HIV-1 cognitive motor complex attribute elevated white matter myo-inositol to increased glial activity (51). Gliosis as a cause for increased myo-inositol in these infants with NE is unlikely as they were studied so acutely after the insult; furthermore, recent studies have demonstrated that myoinositol is not a specific marker of glia (52).

In this study, brain lactate/Cr was increased in infants with an abnormal neurodevelopmental outcome; these results confirm previous studies investigating changes in brain lactate $/ \mathrm{Cr}$ within the first week of life and subsequent neurodevelopmental outcome $(16,34,53)$. In addition, this study demonstrates an association between early increases in lactate/ $\mathrm{Cr}$ and myoinositol/Cr and a possible relationship between these biochemical changes and MRI abnormalities.

We demonstrated that brain NAA/Cr measured at a mean of $3.5 \mathrm{~d}$ was not significantly related to $m y o$-inositol/Cr nor was it reduced in infants with an abnormal neurodevelopmental outcome. There was not a relationship between NAA/Cr and MRI abnormalities. NAA/Cr in the normal outcome group demonstrated a wider spread than $\mathrm{NAA} / \mathrm{Cr}$ in the abnormal group. Previous studies in infants with NE at $<1$ wk of age (median, 1.8 d) concur with our findings (34); studies conducted in infants with $\mathrm{NE}$ at $\geq 1$ wk of age have demonstrated a decrease in NAA/Cr (19) and NAA/Cho (53) ratios in infants with a poor neurodevelopmental outcome. This delay in reduction in $\mathrm{NAA} / \mathrm{Cr}$ or NAA/Cho may indicate that neuronal loss occurred during a prolonged time or that a reduced NAA concentration may be masked by increased metabolite $T_{2}$ values during secondary energy failure (54).

Brain $\mathrm{Cho} / \mathrm{Cr}$ measured at a mean of $3.5 \mathrm{~d}$ was not significantly related to $m y o$-inositol/Cr nor was it reduced in infants with an abnormal neurodevelopmental outcome. There was not a relationship between $\mathrm{Cho} / \mathrm{Cr}$ and MRI abnormalities. Previous studies have suggested a decrease in Cho after perinatal HI (33); however, this did not reach significance in our study.

In summary, myo-inositol has several important roles in the $\mathrm{CNS}$, one of which is cell volume regulation during persistent osmotic stress. myo-Inositol may also play a part in the response to HI injury. Our preliminary data suggest that at a mean age of $3.5 \mathrm{~d}$, brain $m y o$-inositol/Cr was increased in the basal ganglia of infants with $\mathrm{NE}$ with severe brain injury as evidenced by increased lactate/Cr, abnormal MRI, and an abnormal neurodevelopmental outcome at $1 \mathrm{y}$.

\section{REFERENCES}

1. Yancey PH, Clark EM, Hand CS, Bowlus DR, Sonera NG 1982 Living with water stress: evolution of osmolyte systems. Science 217:1214-1222

2. Kwon HM, Yamauchi A, Uchida S, Preston SA, Garcia-Perez AM, Burg B, Handler SJ 1992 Cloning of the cDNA for a Na$/ m y o$-inositol cotransporter, a hypertonicity stress protein. J Biol Chem 267:6297-6301

3. Novak JE, Agranoff BW, Fisher SK 2000 Regulation of myo-inositol homeostasis in differentiated human NT2-N neurons. Neurochem Res 25:561-566

4. Lee JH, Arcinue E, Ross BD 1994 Brief report: organic osmolytes in the brain of an infant with hypernatremia. N Engl J Med 331:439-499 
5. Wiese JT, Dunlop AJ, Conner EC, Grzybowski AJ, Lowe LW, Yorek MA 1996 Osmotic regulation of Na-myo-inositol cotransporter mRNA level and activity in endothelial and neural cells. Am J Physiol 270:C990-C997

6. Strange K, Emma F, Parades A, Morrison R 1994 Osmoregulatory changes in myo-inositol content and $\mathrm{Na}^{+} /$myo-inositol cotransport in rat cortical astrocytes. Glia 12:35-43

7. Parades A, MacManus M, Kwon HM, Strange K 1992 Osmoregulation of $\mathrm{Na}^{+} / m y o-$ inositol cotransporter activity and mRNA levels in brain glial tissue Am J Physiol 263:C1282-C1288

8. Hatashita S, Hoff JT, Salamat MS 1988 Ischemic brain edema and the osmotic gradient between blood and brain. J Cereb Blood Flow Metab 8:552-559

9. Schuier JF, Hossmann KA 1980 Experimental brain infarction in cats. Stroke 11:593-600

10. Yamashita T, Kohmura E, Yamauchi A, Shimada S, Yuguchi T, Sakaki T, Miyai A, Tohyama M, Hayakawa T 1996 Induction of $\mathrm{Na}^{+} /$myo-inositol cotransporter mRNA after focal cerebral ischemia: evidence for extensive osmotic stress in remote areas. J Cereb Blood Flow Metab 16:1203-1210

11. Yamashita T, Shimada S, Yamauchi A, Guo W, Kohmura E, Hayakawa T, Tohyama M 1997 Induction of $\mathrm{Na}^{+} /$myo-inositol cotransporter mRNA after rat cryogenic injury. Mol Brain Res 46:236-242

12. Yamashita T, Yamauchi A, Miyai A, Taniguchi M, Yoshimine T, Tohyama M 1999 Neuroprotective role of $\mathrm{Na}^{+} /$myo-inositol cotransporter against veratridine cytotoxicity. J Neurochem 72:1864-1870

13. Lorek A, Takei Y, Cady EB, Wyatt JS, Penrice J, Edwards AD, Peebles D, Wyelinska M, Owen-Reece H, Kirkbride V, Cooper CE, Aldridge RF, Roth RF, Brown G, Delpy DT, Reynolds EOR 1994 Delayed ("secondary") cerebral energy failure after acute hypoxia-ischemia in the newborn piglet: continuous 48-hour studies by phosphorus magnetic resonance spectroscopy. Pediatr Res 36:699-706

14. Penrice J, Lorek A, Cady EB, Amess PN, Wyelinska M, Cooper CE, D'Souza P, Brown GC, Kirkbride V, Edwards AD, Wyatt JS, Reynolds EOR 1997 Proton magnetic resonance spectroscopy of the brain during acute hyopoxia-ischemia and delayed cerebral energy metabolism in the newborn piglet. Pediatr Res 41:795-802

15. Azzopardi D, Wyatt JS, Cady EB, Delpy DT, Baudin J, Stewart AL, Hope PL, Hamilaton PA, Reynolds EOR 1989 Prognosis of newborn infants with hypoxicischemic brain injury assessed by phosphorus magnetic resonance spectroscopy. Pediatr Res 25:445-451

16. Hanrahan D, Cox IJ, Azzopardi D, Cowan FM, Sargentoni J, Bell JD, Bryant DJ, Edwards AD 1999 Relation between proton magnetic resonance spectroscopy within 18 hours of birth asphyxia and neurodevelopmental outcome at one year of age. Dev Med Child Neurol 41:76-82

17. Robertson NJ, Cowan FM, Cox IJ, Edwards AD 1999 Brain intracellular pH measured by phosphorus-31 magnetic resonance spectroscopy correlated with outcome after perinatal asphyxia. Early Hum Dev 54:76-77(abstr)

18. Roth SC, Baudin J, Cady E, Johal K, Townsend JP, Wyatt JS, Reynolds EOR, Stewart AL 1997 Relation of deranged neonatal cerebral oxidative metabolism with neurodevelopmental outcome and head circumference at 4 years. Dev Med Child Neurol 39:718-725

19. Robertson NJ, Cox IJ, Cowan FM, Counsell SJ, Azzopardi D, Edwards AD 1999 Cerebral intracellular lactic alkalosis persisting months after neonatal encephalopathy measured by magnetic resonance spectroscopy. Pediatr Res 46:287-296

20. Rutherford MA, Pennock JM, Counsell SJ, Mercuri E, Cowan FM, Dubowitz LMS, Edwards AD 1998 Abnormal magnetic resonance signal in the internal capsule predicts poor neurodevelopmental outcome in infants with hypoxic-ischemic encephalopathy. Pediatrics 102:323-328

21. Jackson PS, Morrison R, Strange K 1994 The volume-sensitive organic osmolyteanion channel VSOAC is regulated by nonhydrolytic ATP binding. Am J Physiol 267:C1203-C1209

22. Azzopardi D, Robertson NJ, Cowan FM, Rutherford MA, Rampling M, Edwards AD 2000 Pilot study of whole body hypothermia for neonatal encephalopathy. Pediatrics 106:684-694

23. Bottomley PA 1987 Spatial localization in NMR spectroscopy in vivo. Ann NY Acad Sci 508:333-348

24. Ross BD 1991 Biochemical considerations in ${ }^{1} \mathrm{H}$ spectroscopy. Glutamate and glutamine: myo-inositol and related metabolites. NMR Biomed 4:59-63

25. Michaelis T, Merboldt KD, Hanicke W, Gyngell ML, Bruhn H, Frahm J 1991 On the identification of cerebral metabolites in localised ${ }^{1} \mathrm{H}$ NMR spectra of human brain in vivo. NMR Biomed 4:90-98

26. Griffiths R 1970 The abilities of babies. University of London Press, London

27. Haataja L, Mercuri E, Regev R, Cowan FM, Rutherford MA, Dubowitz V, Dubowitz L 1999 Optimality score for the neurologic examination of the infant at 12 and 18 months of age. J Pediatr 135:153-61

28. Kreis R, Ernst T, Ross BD 1993 Development of the human brain: in vivo quantification of metabolite and water content with proton magnetic resonance spectroscopy. Magn Reson Med 30:424-437
29. Amess PN, Penrice J, Cady EB, Lorek A, Wyelinska M, Cooper CE, D'Souza P, Tyszczuk L, Thoresen M, Edwards AD, Wyatt JS, Reynolds EOR 1997 Mild hypothermia after severe transient hypoxia-ischemia reduces the delayed rise in cerebral lactate in the newborn piglet. Pediatr Res 41:803-808

30. Thoresen M, Penrice J, Lorek A, Cady EB, Wyelinska M, Kirkbride V, Cooper CE, Brown GC, Edwards AD, Wyatt JS, Reynolds EOR 1995 Mild hypothermia after severe transient hypoxia-ischemia ameliorates delayed cerebral energy failure in the newborn piglet. Pediatr Res 37:667-670

31. Sprung J, Cheng EY, Gamulin S, Kampine JP, Bosnjak ZJ 1991 Effects of acute hypothermia and beta-adrenergic receptor blockade on serum potassium concentration in rats. Crit Care Med 19:1545-1551

32. Guignard JP, Gillieron P1997 Effect of modest hypothermia on the immature kidney Acta Pediatr Scand 86:1040-1041

33. Cady EB 1996 Metabolite concentrations and relaxation in perinatal cerebral hypoxicischemic injury. Neurochem Res 21:1043-1052

34. Penrice J, Cady EB, Lorek A, Wyelinska M, Amess P, Aldridge R, Stewart A, Wyatt J 1996 Proton magnetic resonance spectroscopy of the brain in normal preterm and term infants and early changes after perinatal hypoxia-ischemia. Pediatr Res 40:6-14

35. Behar KL, Rothman DL, Spencer DD, Petroff OAC 1994 Analysis of macromolecule resonances in ${ }^{1} \mathrm{H}$ NMR spectra of human brain. Magn Reson Med 32:294-302

36. Saunders DE, Howe FA, van den Boogaart A, Griffiths JR, Brown MM 1997 Discrimination of metabolite from lipid and macromolecule resonances in cerebral infarction in humans using short echo proton spectroscopy. J Magn Reson Imaging $7: 1116-1121$

37. Govindaraju V, Young K, Maudsley AA 2000 Proton NMR chemical shifts and coupling constants for brain metabolites. NMR Biomed 13:129-153

38. Law RO 1991 Amino acids as volume-regulatory osmolytes in mammalian cells Comp Biochem Physiol A Physiol 99:263-277

39. Berridge MJ 1993 Inositol triphosphate and calcium signalling. Nature 361:315-325

40. Thurston JH, Sherman WR, Haubart RE, Kloepper RF 1989 myo-Inositol: a newly identified non-nitrogenous osmoregulatory molecule in mammalian brain. Pediatr Res 26:482-485

41. Bachelard H 1997 Localized proton magnetic resonance spectroscopy of brain disorders in childhood. In: Magnetic Resonance Spectroscopy and Imaging in Neurochemistry. Plenum Press, New York, p 337

42. Guo W, Shimada S, Tajiri H, Yamauchi A, Yamashita T, Okada S, Tohyama M 1997 Developmental regulation of $\mathrm{Na}^{+} / m y o$-inositol cotransporter gene expression. $\mathrm{Mol}$ Brain Res 51:91-96

43. Videen JS, Michaelis T, Pinto P, Ross BD 1995 Human cerebral osmolytes during chronic hyponatremia. A proton magnetic resonance spectroscopy study. J Clin Invest 95:788-793

44. Lang F, Busch GL, Ritter M, Volk1 H, Waldegger S, Gulbins E, Haussinger D 1998 Functional significance of cell volume regulatory mechanisms. Physiol Rev 78:247306

45. Miller B, Moats RA, Shonk T, Ernst T, Wooley S, Ross BD 1993 Alzheimer disease: depiction of increased cerebral myo-inositol with proton MR spectroscopy. Radiology 187:433-437

46. Robertson NJ, Kuint J, Counsell SJ, Rutherford MA, Coutts GA, Cox IJ, Edwards AD 2000 Characterization of cerebral white matter damage in preterm infants using ${ }^{1} \mathrm{H}$ and ${ }^{31} \mathrm{P}$ magnetic resonance spectroscopy. J Cereb Blood Flow Metab 20:1446-1456

47. Berry GT, Wang ZJ, Dreha SF, Finucane BM, Zimmerman RA 1999 In vivo brain myo-inositol levels in children with Down syndrome. J Pediatr 135:94-97

48. Berry GT, Mallee JJ, Kwon HM, Rim JS, Mulla WR, Muenke M, Spinner NB 1995 The human osmoregulatory $\mathrm{Na}^{+} /$myo-inositol cotransporter gene (SLC5A3): molecular cloning and localization to chromosome 21. Genomics 25:507-513

49. Fruen BR, Lester BR 1990 Down's syndrome fibroblasts exhibit enhanced mI uptake. Biochem J 270:119-123(abstr)

50. Brand A, Richter-Landsberg C, Leibfritz D 1993 Multinuclear NMR studies on the energy metabolism of glial and neuronal cells. Dev Neurosci 15:289-298

51. Chang L, Ernst T, Leonido-Yee M, Walot I, Singer E 1999 Cerebral metabolite abnormalities correlate with clinical severity of HIV-1 cognitive motor complex. Neurology 52:100-108

52. Novak JE, Turner RS, Agranoff BW, Fisher SK 1999 Differentiated human NT2-N neurons possess a high intracellular content of myo-inositol. J Neurochem 72:14311440

53. Groenendaal F, Veenhoven RH, van dre Grond J, Jansen GH, Witkamp TD, de Vries LS 1994 Cerebral lactate and $N$-acetyl-aspartate/choline ratios in asphyxiated fullterm neonates demonstrated in vivo using proton magnetic resonance spectroscopy. Pediatr Res 35:148-151

54. Cady EB, Lorek A, Penrice J, Wyelinska M, Cooper CE, Brown GC, Owen-Reece H, Kirkbride V, Wyatt JS, Reynolds EOR 1994 Brain-metabolite transverse relaxation times in magnetic resonance spectroscopy increase as adenosine triphosphate depletes during secondary energy failure following acute hypoxia-ischaemia in the newborn piglet. Neurosci Lett 182:201-204 